\title{
Can malt whisky be discriminated from blended whisky? The proof. A modification of Sir Ronald Fisher's hypothetical tea tasting experiment
}

\author{
STEPHEN J D CHADWICK, HUGH A F DUDLEY
}

\begin{abstract}
A modified version of Fisher's tea tasting experiment was performed to test the confident assertions of some members of an academic surgical unit that they could easily distinguish malt from blend whisky. Eight male volunteers from the unit, divided into regular and inexperienced whisky drinkers, were blindfolded and given a giass of each of six whiskies. The whiskies included three malts and three blends, and each subject tasted each whisky six times. They were asked whether the whisky was malt or blended, whether they could identify the distillery, and whether they liked it (ranked on a ninepoint scale). The four regular whisky drinkers identified the whiskies as malts 57 times, as blends 84 times, and did not know three times; the inexperienced drinkers identified them as malts 64 times, as blends 79 times, and did not know on one occasion. The regular drinkers correctly identified the malts 36 times and the blends 48 times, and the inexperienced drinkers correctly identified malts 30 times and blends $\mathbf{4 0}$ times. Statistical analysis of the data suggested that within the unit malt whisky could not be distinguished from blended whisky and that experience did not alter powers of discrimination. A surgeon with no discriminatory prowess at all could be expected to achieve complete discrimination of malt from blend whisky once in $2^{36}$ occasions.

These results suggest that, although "uisgebeatha" has unique properties, the inexpert drinker should choose his whisky to suit his taste and pocket and not his self image.
\end{abstract}

\section{Introduction}

Whisky drinkers often assert that malt may be discriminated from blend. The ability to discriminate plays a part in establishing a social order among whisky drinkers, and, certainly on our unit, confident statements are frequently made by soidisant experts.

In the first edition of his classic Design of Experiments Sir Ronald Fisher described a hypothetical experiment (we have been unable to confirm whether it has ever been put into practice) which tested the ability of an aristocratic lady to distinguish between cups of tea that had been poured with the milk before the tea and those that had been poured with the milk after the tea. ${ }^{1}$ To settle the issue for whisky-as consumed by amateurs at least-we resolved to use an adaptation of Fisher's design.

\footnotetext{
Academic Surgical Unit, St Mary's Hospital Medical School, London $\mathrm{W} 2$

STEPHEN J D CHADWICK, FRCS, research fellow and honorary senior registrar

HUGH A F DUDLEY, CHM, FRCS, professor of surgery
}

\section{Subjects and methods}

Eight men, all members of our surgical unit (clinical and research), readily volunteered to take part in the experiment. Two weeks before the experiment they were informed that three examples of malt whisky would be chosen to represent three distinct areas of production-that is, Speyside, west coast, and north eastern-and that three popular blends would be used (table I).

TABLE I-Types of whisky tested with comments on their aroma and taste

\begin{tabular}{|c|c|c|c|c|}
\hline Whisky & Volume & Source & Nose & Palate \\
\hline \multicolumn{5}{|c|}{ Mults } \\
\hline Glenfiddich & $40^{\prime \prime}$ & Speyside & $\begin{array}{l}\text { Light delicate } \\
\text { peatiness }\end{array}$ & $\begin{array}{l}\text { Lingering sweet } \\
\text { delicate flavour }\end{array}$ \\
\hline Springbank & $40 "$. & West codst & $\begin{array}{l}\text { Medium to full } \\
\text { bodied aroma }\end{array}$ & $\begin{array}{l}\text { Well matured, very } \\
\text { full, lingering }\end{array}$ \\
\hline Glenmorangie & $40 "$. & Nurth eastern & $\begin{array}{l}\text { Medium aroma, } \\
\text { sweet, subtle } \\
\text { smokiness }\end{array}$ & $\begin{array}{l}\text { Touch of sweetness, } \\
\text { smooth and } \\
\text { mellow }\end{array}$ \\
\hline \multicolumn{5}{|c|}{ Blends } \\
\hline Bells & $40 "$. & & Very sweet & $\begin{array}{l}\text { Much better than } \\
\text { nose denoted }\end{array}$ \\
\hline $\begin{array}{l}\text { Haig } \\
\text { White Horse }\end{array}$ & $\begin{array}{l}40 ", " \\
40 ",\end{array}$ & & $\begin{array}{l}\text { Heavy aroma } \\
\text { Slight hint of } \\
\text { smokiness }\end{array}$ & $\begin{array}{l}\text { Light smooth flavour } \\
\text { Fulsome, mellow, } \\
\text { and smooth }\end{array}$ \\
\hline
\end{tabular}

TABLE II-Distribution of all answers and correct answers among the two groups of drinkers ("don't know" zvas classified as incorrect). Results are numbers (and percentages

\begin{tabular}{lllc}
\hline & Malts & Blends & Don't know \\
\hline Regular whisky drinkers: & $57(40)$ & $84(58)$ & $3(2)$ \\
$\quad$ Total answers out of 144 & $36(50)$ & $48(67)$ & \\
$\quad$ Correct answers out of 72 & $64(44)$ & $79(55)$ & $1(1)$ \\
$\begin{array}{l}\text { Inexperienced whisky drinkers: } \\
\quad \text { Total answers out of } 144\end{array}$ & $32(44)$ & $40(56)$ & \\
Correct answers out of 72 &
\end{tabular}

Each subject was tested, seated and blindfolded, after the evening ward round. A sherry copita with approximately a single measure of a whisky chosen independently at random and to which a "thimbleful" $(5 \mathrm{ml})$ of spring water had been added was given to him. He was invited to smell the whisky and then to taste it. Two direct questions were asked and a score based on a Hedonic scale requested":

(1) Is it "malt," "blend," or "don't know ?"

(2) Can you identify the distiller?

(3) Score from 1-9 how you liked or disliked the drink (1 meaning "dislike extremely," 5 "neither dislike nor like," and 9 "like extremely").

Each whisky was tasted by each individual six times.

\section{Results}

The eight subjects could be conveniently divided into two groups of four, according to how often they drank whisky. Thus, those who drank whisky more often than twice a fortnight were termed regular drinkers, and those who drank whisky less than this inexperienced drinkers.

Table II shows the distribution of all answers and correct answers ("don't know" was classified as incorrect).

To test the hypothesis that the correct choice of malt or blend for each whisky was random, a one sample $\%^{2}$ test was used. 
Regular drinkers $y^{2}-7 \cdot 15, \mathrm{df}-5,0 \cdot 3>\mathrm{p}>0 \cdot 2$

Inexperienced drinkers $\gamma^{2}-3.99$, df $-5,0.7>p>0.5$

To test the hypothesis that the choices of malt or blend were random a two sample $\gamma^{2}$ was used.

Regular drinkers $\%^{2}-4.83, \mathrm{df}-1, \mathrm{p}<0.05$

Inexperienced drinkers $\gamma^{2}-2 \cdot 25, \mathrm{df}-1,0 \cdot 2>\mathrm{p}-0 \cdot 1$

The most popular whisky was Glenfiddich, with a mean score of 33.4 (SD 8.8); the most popular blend was White Horse with a mean score of 31.63 (SD 9.0).

To test whether any whisky was more favoured, we ranked the individual scores of all six whiskies in both groups and used the Kruskall-Wallis one-way analysis of variance: $\mathrm{H}=3.90, \mathrm{df}=5$, $0 \cdot 70 \quad \mathrm{p} \cdot \mathbf{0} \cdot \mathbf{5 0}$.

To determine whether a preference for malt or blended whisky existed we applied the Mann-Whitney $U$ test: $z=1.45, p=0.0735$.

Of 93 attempts to identify the whisky tasted, only one person on one "tasting" positively identified the area of the production of the malt (Springbank). He was unable to give the distiller's name. When tested again during the experiment he failed to identify the whisky. When challenged after the experiment, however, he could clearly remember the drink and his experience.

\section{Discussion}

The data confirm the null hypothesis that, within our unit, malt cannot be distinguished from blended whisky and that experience does not alter powers of discrimination. Regular drinkers were able to detect blends more easily than malts only because of the frequency with which they gave the answer "blend," though again this was no better than random.

We have analysed the Hedonic scores of the eight subjects as one group, so that at future social gatherings no pecuniary disadvantage will occur to our funds; so long as the lights are dimmed and the label is covered we ma drink and enjoy our whisky in blissful ignorance.

We did not follow Sir Ronald Fisher's experimental design precisely, as we used three varieties of each whisky. We have tested the dogma of our colleagues that malt has a unique (and universal) feature that makes it clearly distinguishable from blended whisky. Our statistical analysis was entirely nonparametric, although by randomisation and testing six samples of each whisky a subject with no discriminatory prowess at all could be expected to achieve complete discrimination of malt from blended once in $2^{36}$ ( 1 in $6.87 \times 10^{10}$ ) occasions.

Although we could not draw any statistical inferences intuitively we felt that the performance of our subjects was influenced by extraneous factors, such as mood and compliance.

Thus, in conclusion, we certainly agree that "uisgebeatha" has unique properties steeped in romance and mystique but that the inexpert drinker should choose his whisky to suit his taste (and his pocket) and not his self image.

We wish to thank Wallace Milroy for choosing the whiskies and for his expert advice and support given during this study.

\section{References}

${ }^{1}$ Fisher RA. The design of experiments. 7th ed. Edinburgh: Oliver Boyd, 1960:11-26.

2 Larmond E. Laboratory Methods for Sensory Evaluation of Food. Ottawa Department of Publication (1637), 1977:56-7.

\section{Peer commentaries and riposte}

Some journals-most notably The Behavioural and Brain Sciences-print peer commentaries on the articles they publish and invite the authors to riposte. We have done the same for the article on whisky testing by Chadwick and Dudley: Sir James Howie, a former director of the Public Health Laboratory Service, is a distinguished amateur expert on whisky and Douglas Altman is a statistician working at the Medical Research Council's Clinical Research Centre at Northwick Park Hospital.

\section{Good motivation but indifferent methods}

\section{JAMES HOWIE}

The authors are clearly motivated by a fine judgment of what is a worthy subject. Alas, their handling of the raw material (if raw is a proper word to use in this context) is such that I cannot advise you to include this article in any copies of your journal destined for Scotland or indeed for any part of the world where there are truly discriminating drinkers of whisky. The authors are right in thinking that there are many phoney connoisseurs of whisky and that their claims to distinguish malt from blended whisky and one whisky from another should be exposed for the nonsense they often are. But the choice of malts and blends indicated in the table is such that a clear cut result could scarcely be expected.

To be specific: Glenfiddich, pure nectar to my friendly psychiatrist, is one of the most thoroughly advertised of Speyside whiskies and sells uncommonly well in the USA. On Speyside itself, however, if you wish to do justice to that sacred area, you have a choice of three superb malts: Macallan (of a good year); Glen Grant 15 years old; and the Glenlivet at least 12 years old better 15. My own choice would be a Macallan 1952 (not 1954) matured for 15 years or a Glen Grant matured for 15 years. The Glenlivet, of course, is different from many other Speyside whiskies which have stuck "Glenlivet" on their labels, although they are not produced in the parish of Glenlivet. Any one of these three, however, has a depth of flavour and a mellowness on the palate that entitles it to be accepted as an aristocrat of Speyside, as distinct from being perhaps merely the best known. I should find it hard to distinguish among these three of the right age, and year if applicable; but I could tell them from a strongly peat flavoured Island malt such as Talisker (Isle of Skye) or Laphroig (Isle of Islay). I confess that I do not know Springbank, which is an ignorance I must try to deal with.

Glenmorangie is deservedly popular, but it is not very easy to be sure of its identity as against Glenfiddich, a point that is hinted at in the "palate" assessments in table I, both being correctly identified as having a sweetish flavour. To Daiches, a very good authority, Glenmorangie was at one time his favourite malt, but he later revised this judgment, as I understand. So, I suggest that, if the authors wish to be taken seriously, they should repeat the work with three truly distinctive malts, Glen Grant (15 years matured); Laphroig (10 years old or more); and Glen Dronach (10-12 years old), a true representative, and a very fine one, of a north eastern whisky.

As to the choice of blends, it is important not to be so determinedly basic as to go for Bells, Haig, and White Horse-all good value for the money-but not really to be compared for distinctiveness with aristocratic blends such as Antiquary, Crawford's 5-star, or Johnnie Walker Black Label. I think that these could be identified from each other and from malts by real connoisseurs. 